\title{
Applying Time-Frequency Distribution Function to DOA of Mobile Active Sensor
}

\author{
Shun-Hsyung Chang \\ Department of Electrical Engineering, National Taiwan Ocean University, Keelung, Taiwan, R.O.C. \\ Jun-Cheng Liu \\ Department of Electrical Engineering, National Taiwan Ocean University, Keelung, Taiwan, R.O.C. \\ Chih-Wei Chiu \\ Department of Electrical Engineering, National Taiwan Ocean University, Keelung, Taiwan, R.O.C.
}

Follow this and additional works at: https://jmstt.ntou.edu.tw/journal

Part of the Electrical and Computer Engineering Commons

\section{Recommended Citation}

Chang, Shun-Hsyung; Liu, Jun-Cheng; and Chiu, Chih-Wei (2001) "Applying Time-Frequency Distribution Function to DOA of Mobile Active Sensor," Journal of Marine Science and Technology. Vol. 9: Iss. 2, Article 12.

DOI: 10.51400/2709-6998.2447

Available at: https://jmstt.ntou.edu.tw/journal/vol9/iss2/12

This Research Article is brought to you for free and open access by Journal of Marine Science and Technology. It has been accepted for inclusion in Journal of Marine Science and Technology by an authorized editor of Journal of Marine Science and Technology. 


\section{Applying Time-Frequency Distribution Function to DOA of Mobile Active Sensor}

\section{Acknowledgements}

This work was supported by National Science Council, Republic of China, under Grant NSC88-2218E-019-002. 


\title{
APPLYING TIME-FREQUENCY DISTRIBUTION FUNCTION TO DOA OF MOBILE ACTIVE SENSOR
}

\author{
Shun-Hsyung Chang, Jun-Cheng Liu and Chih-Wei Chiu
}

keywords: direction of arrival, time-frequency distribution function, modified adaptive cone kernel.

\begin{abstract}
Increasing the accuracy of time-frequency detection in engineering is always the goal that scientists are striving to achieve, because it is widely applied in the fields of Radar, Sonar, the exploration of earthquake epicenter etc. The current high-resolution time-frequency methods are mostly based on the structure of time-frequency distribution function of Cohen Family. Time frequency distribution function can trace the instantaneous frequency of nonstationary signal. This paper combines the process principle of multi-aperture Radar and Array signal and applies time-frequency distribution function in DOA of active sensor devices. By decoding of physical characteristics from the changes of frequency, which can be done by using the active devices to detect the response signal of the target and the analyzing the nonstationary changes of frequency caused by the delays of time and phase, the related positions and contained angle of target and reference can be found and practically applied to the target DOA of aircraft and vehicle engineering. By doing that, the troublesome multidimensions Fourier projection calculations, eigen factoring and Spectrum scan can be avoided and reduces the huge amount of active dynamic sensor devices required for vehicles, but not all of the distribution functions can be used to analyze the multi-objects. For example, Wigner distribution function is one of the case, because it contains the high cross-terms and is easily to be interfered by noise. In this paper, the application of a new time-frequency distribution function MACK (Modified Adaptive Cone Kernel) is proposed. The application general form is derived and proved, also the signals of time-varying spectrum are decoded. MACK can eliminate all of the cross-terms and the time-frequency analysis ability is high and uniform. The simulation results showed that the MACK function is very realistic and useful on aircraft navigation and vessel location.
\end{abstract}

\section{INTRODUCTION}

In the application of land, air and sea vehicle use, it is always need to locate and detect the related location of environment. The previous DOA such as MUSIC (MUltiple SIgnal Classification) [1] and ESPRIT (Estimation of Signal Parameters via Rotational Invari- ance Techniques) [2] needs at least three or more sensor to make it work properly, and uses the method of increasing the number of sensor to increase the resolution. Under the limitation of vehicles, only few sensor are allowed in a vehicle, in order to increase the resolution of DOA, a vehicle with good mobility is used. Utilize the generation of displacement to generate the matrix like effect. Measure the changes of frequency and estimate the direction and distance in order to avoid a huge amount of eigen factoring calculation and frequency spectrum scan of MUSIC and ESPRIT. Both of these will influence the real time application of Radar system. During the process of estimating the instantaneous frequency by using Time-Frequency Distribution Function (TFD) [3, 4], it is discovered that it is not only fast and accurate but also there are some relative relationships between the incident angle and distance of signal source, because there exist crossterms in Time-Frequency Distribution Function. MACK (Modified Adaptive Cone Kernel) TFD [5] proposed in this paper uses the method of increasing the operations of kernel resolution to reduce the amount of sensor in order to achieve the fast DOA of short and long distance $[6,7]$.

\section{TIME-FREQUENCY DISTRIBUTION (TFD)}

TFD function is a powerful tool of analyzing the time-varying signals. It can point out the tiny change of frequency at certain time. The basic form of timefrequency function is Wigner Time-Frequency Distribution Function

$$
W D(t, \omega)=\int_{-\infty}^{\infty} s(t+\tau / 2) s^{*}(t-\tau / 2) e^{-j \omega \tau} d \tau
$$

which is the auto-correlation function of Fourier Transform. It has high resolution but contain the crossterms. Thus, it is only suitable for analyzing the single signal source, but not proper to estimate the multiple target. Cohen proposed kernel function $\phi(\theta, \tau)$ [3], and it solves the cross term problem and increases the resolution. The TFD of Cohen family is defined as 


$$
\begin{array}{r}
C(t, \omega, \phi)=\frac{1}{4 \pi} \iiint e^{-j \theta t-j \tau \omega+j \theta u} \phi(\theta, \tau) \\
s^{*}(u+\tau / 2) s(u-\tau / 2) d u d \tau d \theta
\end{array}
$$

MACK TFD proposed in this paper is defined [5] as

$$
\begin{aligned}
W(t, \omega) & =\int e^{-j \omega t} \int_{t-a|\tau|}^{t+a|\tau|} e^{-\frac{(\mu-t)^{2} \tau^{2}}{\rho^{2}}} \\
& s^{*}\left(\mu-\frac{\tau}{2}\right) s\left(\mu+\frac{\tau}{2}\right) d u d \tau \\
\phi(\theta, \tau)= & \int_{-a|\tau|}^{a|\tau|} e^{-\frac{(u-t)^{2} \tau^{2}}{\rho^{2}}+j \theta(u-t)} d(u-t) \\
= & \int_{-a|\tau|}^{a|\tau|} e^{-\frac{-k^{2} \tau^{2}}{\rho^{2}}+j \theta_{k}} d k
\end{aligned}
$$

The idea of MACK TFD is to find out kernel function and do cone region Fourier transform in $(t, \tau)$ plane, because the operations in $(t, \tau)$ plane can simplify tree-integration and the operations of kernel function can suppress cross-terms and enhance the resolution. Taking regional Fourier transform makes it not divergence and the changes of cone slope has good filter effect $[8,9,10]$.

In the above equation, $\phi(\theta, \tau)$ is called kernel function, and $s(u)$ is time signal. Wigner kernel distribution function is [3]

$$
\phi(\theta, \tau)=1
$$

And exponential kernel function is [8]

$$
\phi(\theta, \tau)=\exp ^{-\frac{\theta^{2} \tau^{2}}{\rho}}
$$

\section{BEARING AND DISTANCE ESTIMATION}

Assuming it uses a dynamic omni-directional sensor to detect a object with coordinates $(x, y)$, and sensor moves along $Y_{1}$ axis with $V$ velocity. Assume wave speed is $c$ which is very fast and the emit signal is $S(t)$. The characteristic equation is as following $[6,11,12$, 13]

$$
S\left(t-\frac{2 \sqrt{\left(X_{1}-x\right)^{2}+\left(Y_{1}-y\right)^{2}}}{c}\right.
$$

Because wave speed is very fast, if sensor emits omni-directional signals with frequency $\omega_{s}$, there generates the delays of signal time and phase. The distance between sensor and detected object is $\sqrt{\left(X_{1}-x\right)^{2}+\left(Y_{1}-y\right)^{2}}$, and if it is divided by wave speed $c$, then the results are the delays of time and phase. The output signal can be represented as following

$$
y(t)=s(t) e^{j \omega_{s}\left(t-\frac{2 \sqrt{\left(X_{1}-x\right)^{2}+\left(Y_{1}+v t-y\right)^{2}}}{c}\right)}
$$

Assume the emission frequency of active sensor is $\omega_{s}$ which has several signal source equations, and $y(t)$ is the signal received by the sensor and $s(t)$ is the amplitude response of the object after reflection, thus $y(t)$ can be rewritten as

$$
y(t)=\sum_{(x, y)} s(t) e^{j \omega_{s}\left(t-\frac{2 \sqrt{\left(X_{1}-x\right)^{2}+\left(Y_{1}+v t-y\right)^{2}}}{c}\right)}
$$

Obviously, in (9) the phase angle of each term is $\phi$, then the instantaneous frequency for each term is $\frac{d \phi_{x, y}(t)}{d t}$. In order to simplify the analyzing, we let the coordinates of $\left(X_{1}, Y_{1}\right)$ be $(0,0)$, so the time-frequency representation $W(\omega, t)$ can be expressed by

$$
\begin{aligned}
& y(t)=\sum_{(x, y)} s(t) e^{j \omega_{s}\left(t-\frac{2 \sqrt{x^{2}+(v t-y)^{2}}}{c}\right)} \\
& W(\omega, t)=\sum_{(x, y)} s(t) \delta\left(\omega-\omega_{s}\left(1-\frac{2 v(v t-y)}{c \sqrt{x^{2}+(v t-y)^{2}}}\right)\right) \\
& + \text { cross-terms + noise }
\end{aligned}
$$

The using of high resolution adaptable cone improved kernel function can eliminate unnecessary crossterms and get a high resolution time-frequency distribution function. The characteristic equation is derived as follow,

$$
\omega=\omega_{s}\left(1-\frac{2 v(v t-y)}{c \sqrt{x^{2}+(v t-y)^{2}}}\right)
$$

In Fig. $1 \sin \theta(t)$ can be expressed as

$$
\sin \theta(t)=\frac{(v t-y)}{\sqrt{x^{2}+(v t-y)^{2}}}
$$

And the instantaneous frequency received is

$$
f=f_{s}\left(1-\frac{2 v \sin \theta(t)}{c}\right)
$$

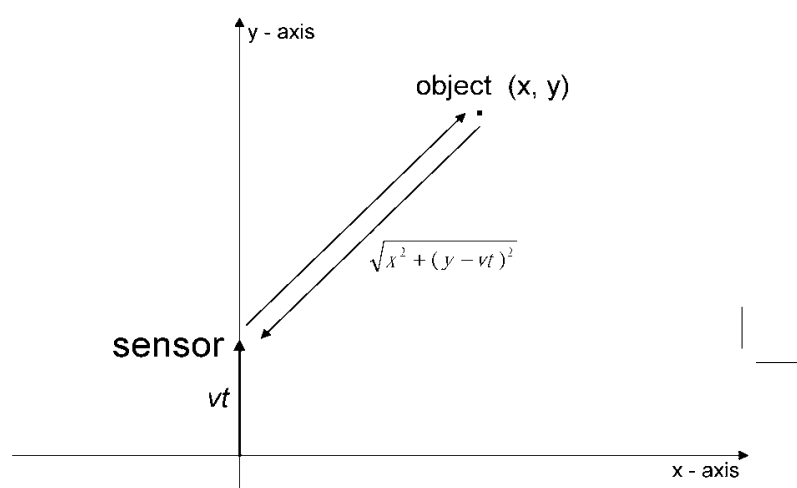

Fig. 1. The coordinate of a dynamic omni-directional sensor. 
In above equations, $f_{s}$ is Radiate Frequency (RF), thus the contain angle of sensor device and estimated object can be derived.

$$
\theta=\sin ^{-1}\left[\frac{c}{2 v}\left(1-\frac{f}{f_{s}}\right)\right]
$$

The relationship between $f$ and $\theta$ is shown in Fig. 2.

How to estimate the distance of object? It can be done by estimating the characteristic equation from moveable bearing (refer to (17) and (13)). Differentiate frequency and the slope of each signal can be find out from the time-frequency relation diagram. Then, according to the slope $\lambda$ (refer to (16)), the mobile DOA distance equation can be found out. If slope is zero, then signal is far away from the sensor. The more the slope is, the closer the object and observer are. Instant range can be represented as follows,

$$
\begin{aligned}
& \lambda=\frac{d f}{d t} \\
& \text { Range }=\left|\frac{v^{2}\left(-\cos ^{2} \theta\right)}{\pi c \lambda}\right|
\end{aligned}
$$

Find out the distance of object and the relative angle $\theta$. If there exist a time-frequency relationship (refer to (15)), then the relative relation of frequency and angle can be found out. Apply time-frequency method to DOA of mobile active sensor and define resolution $R$ (refer to (18)). The faster the moving speed $v$ of the sensor and the frequency of the active sensor are, the better the resolution is. If the target and detected angle increase, then the resolution becomes less sensitive. Thus, it is discovered that the resolution of angle detection on each direction is non-uniform, and shows non-linear changes.

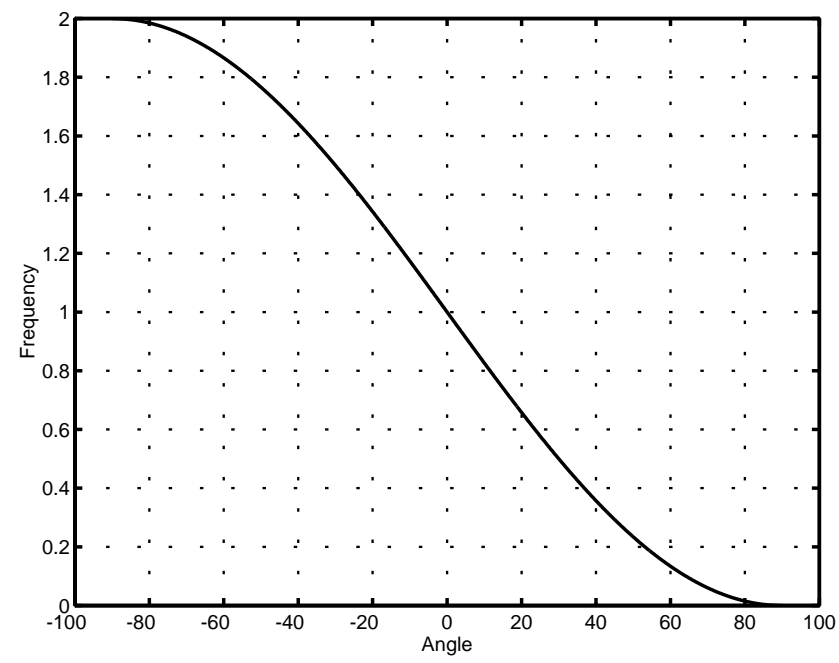

Fig. 2. When $c=2 v$, the relative relation of frequency $f$ and angle $\theta$.

$$
\begin{aligned}
R & =\left|\frac{d f}{d \theta}\right| \\
& =\left|\frac{2 v f_{s} \cos \theta}{c}\right| \\
& =\left|\frac{2 v \cos \theta}{\lambda_{s}}\right|
\end{aligned}
$$

The resolution $R$ of angle detection is shown in Fig. 3.

\section{COMPUTER SIMULATION}

Suppose there are two estimate signal sources, $A$ $(10,10)$ and $B(10000,10000)$, moving at speed $v$ for time $t$ (refer to Fig. 4). Define the reference coordinates sensor moves along $y$ axis and the emission frequency of active sensor is $200 \mathrm{~Hz}$ with wave velocity $331 \frac{\mathrm{m}}{\mathrm{sec}}$ (refer to Fig. 4). Signal is sampled by 322 points. Fig. 5 is the diagram of signals received by sensor in time domain. After evaluating the Fast Fourier Transform of received signal, we can get diagram of signal spectrum (refer to Fig. 6). In Fig. 6, there is a pair of nonstationary signal with central frequency $200 \mathrm{~Hz}$, which has spectrums with two separate peak values. The one with bigger peak value means there is a stationary signal around 100 $\mathrm{Hz}$, but the signal can not be recognized because there is no time scale. The signal got from Wigner timefrequency distribution transform does have very high resolution, but the cross-terms will influence the recognizing of frequency(refer to Fig. 7). Sometimes the energy of cross-terms is higher than the one of autoterms, but if use the exponential time frequency distribution function (refer to Fig. 8) proposed by Choi and Williams, it can be found that almost all cross-terms are suppressed. If we check its resolutions, we can find that

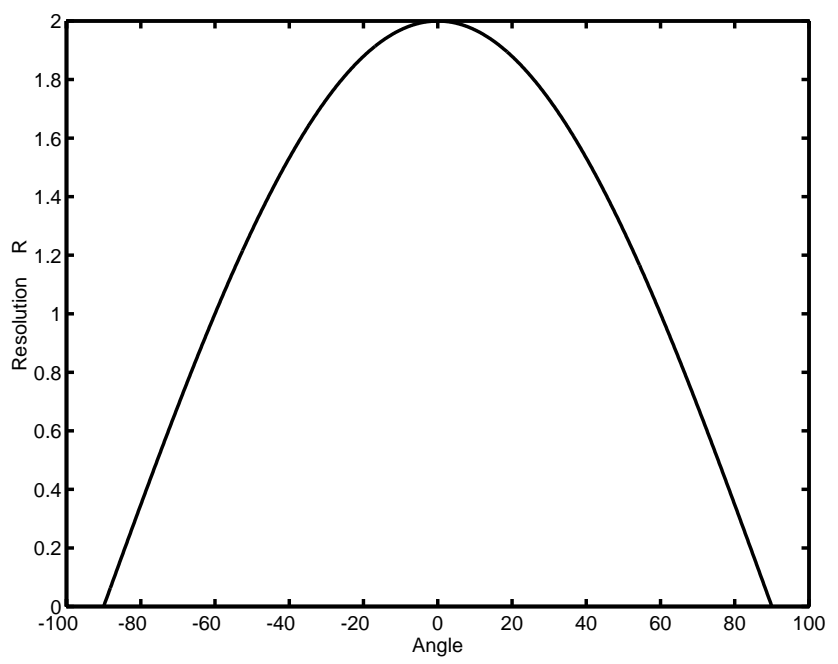

Fig. 3. When $f_{s}=1, c=2 v$, the resolution $R$ of angle detection. 


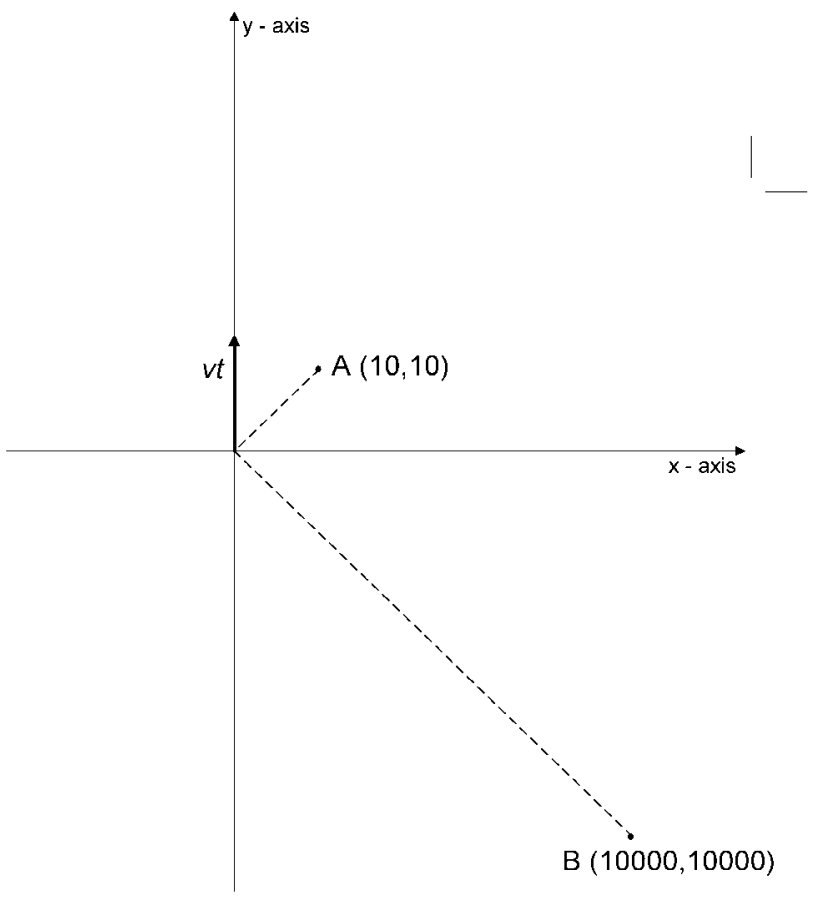

Fig. 4. The two estimated signal sources, $A(10,10)$ and $B(10000,10000)$.

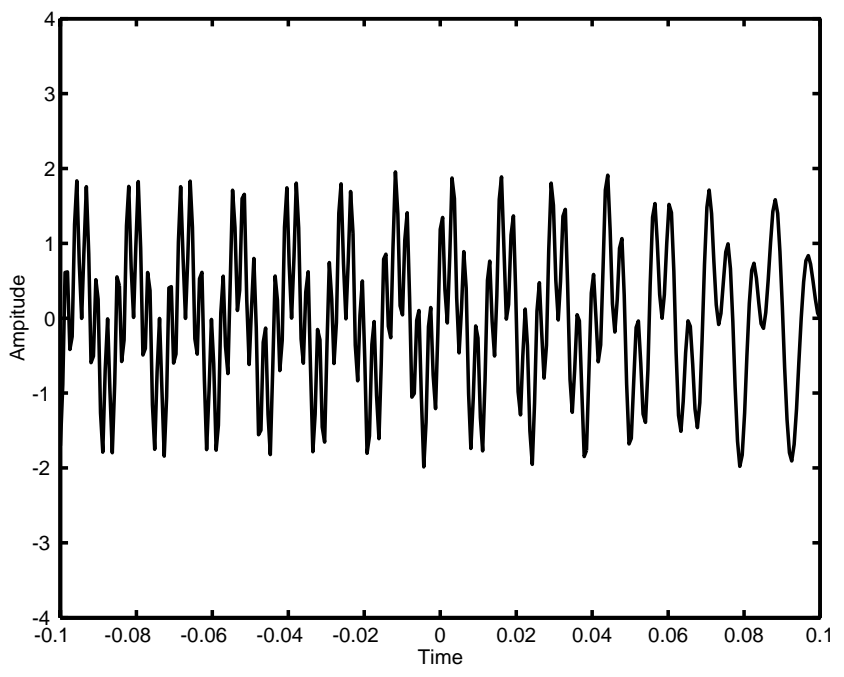

Fig. 5. Signal received by sensor in time domain.

the resolution is becoming worse when the signal is nonstationary. If there is a nearby signal, then the contour diverges and it is unanalyzable. Using MACK time-frequency distribution proposed by us (refer to Fig. 9), nearly all of the cross-terms are eliminated and the time-frequency analysis ability is high and uniform. The correct result can be derived through transforming the received frequency to the relationship of angle and distance (refer to Fig. 4).

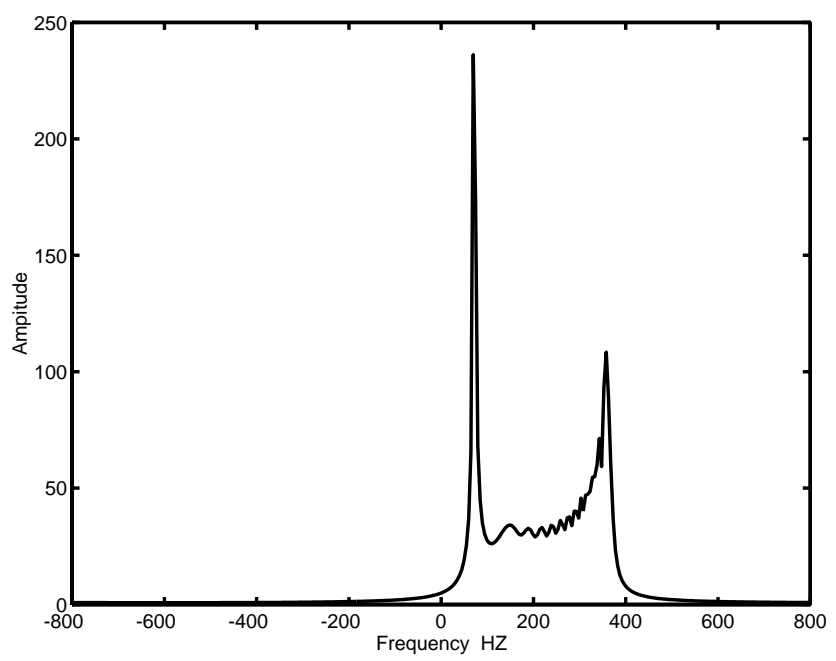

Fig. 6. Signal received by sensor in frequency domain.

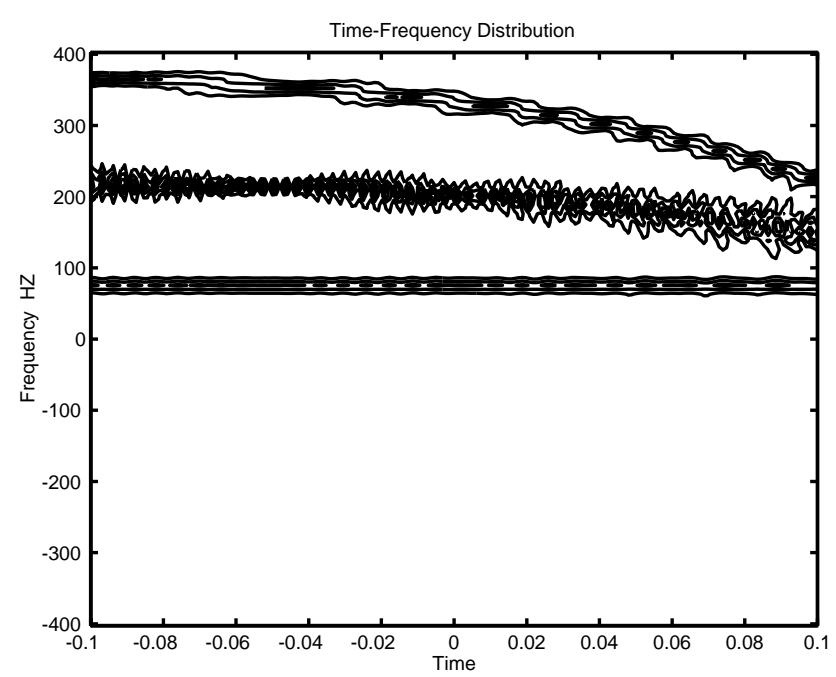

Fig. 7. Using the Wigner time-frequency distribution transform to analyze signal sources.

\section{CONCLUSION}

From above method of applying time-frequency distribution function to DOA, it is understood that the time-frequency distribution function applying on the long range DOA is a stationary signal in time-frequency diagram, and is a nonstationary signal on short range DOA. Nonstationary signal can not recover signal only through simple Fast Fourier Transform. From the time scale, frequency scale and the changes of time and frequency in two dimension time-frequency diagram, it is easy to detect the important information implied in instantaneous frequency. The using of mobile active DOA, if the location and instantaneous speed can be 


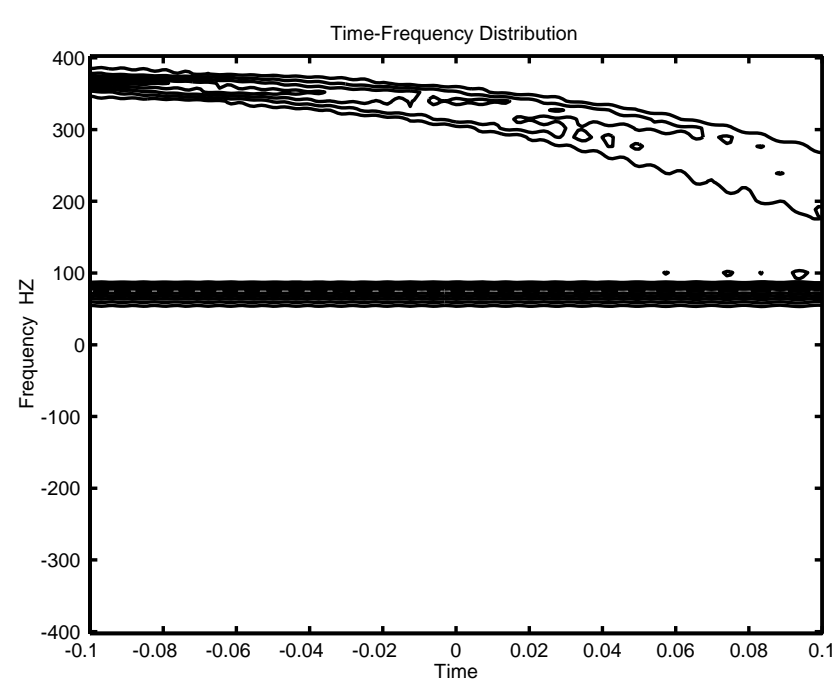

Fig. 8. Using the exponential time-frequency distribution transform to analyze signal sources.

determined, make it easy to find out the direction and distance of the estimating object. The advantage of this kind of mobile sensor is that we only need to enhance the eliminating cross-terms ability of kernel function, then we can get a high resolution information. It is not necessary to use many expensive sensors and spend a lot of calculation time on eigen factoring by using traditional method. The application of time-frequency distribution function on aircraft navigation and vessel location is very realistic and useful.

\section{ACKNOWLEDGEMENT}

This work was supported by National Science Council, Republic of China, under Grant NSC88-2218E-019-002.

\section{REFERENCES}

1. R. O. Schmidt, "Multiple emitter location and signal parameter estimation," Proc. RADC Spectrum Estimation Workshop, Rome, NY, 1979.

2. R. Roy and T. Kailath, "ESPRIT-estimation of signal parameters via rotational invariance techniques," IEEE Trans. on Acoustics, Speech, and Signal Processing, Vol. 37, pp. 984-995, 1989.

3. Leon Cohen, Time-Frequency Analysis, Prentice-Hall, Englewood Cliffs, New Jersey, 1994.

4. B. Boashash, Time-Frequency Signal Analysis Methods and Applications, Wiley Halsted Press, 1992.

5. J. C. Liu, "On Signal Detection Using Adaptive ConeKernel Time-Frequency Representation," National Tai-

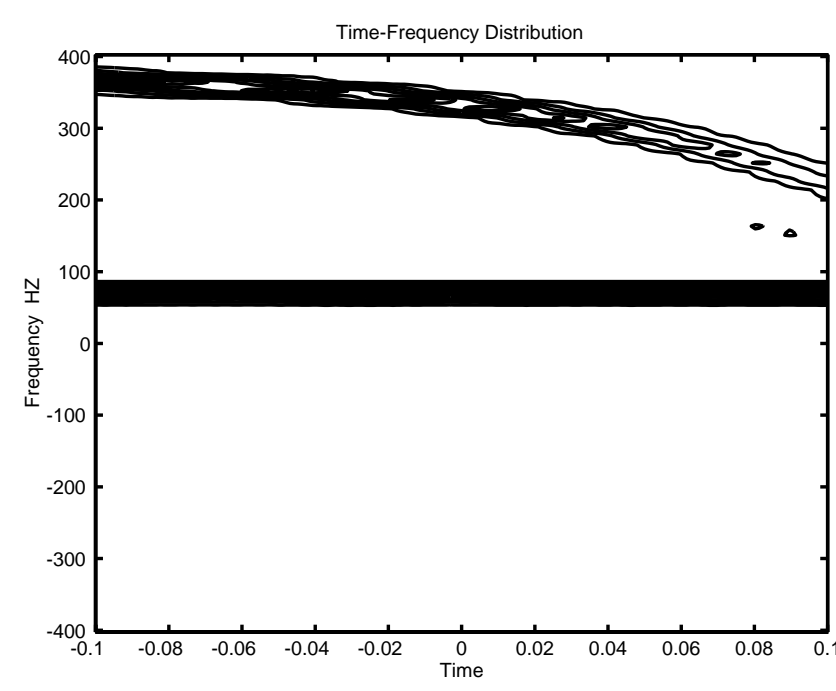

Fig. 9. Using the MACK time-frequency distribution transform to analyze signal sources.

wan Ocean University, Keelung, Taiwan, 1997(in Chinese).

6. Mehrdad Soumekh, Fourier Array Imaging, PrenticeHall, Englewood Cliffs, New Jersey, 1994.

7. S. H. Chang, W. W. Lin, and W. H. Fang, "A Fast NearField Bearing Estimation Via Spatial Exponential Kernel Distribution," IX European Signal Processing Conference, Eusipco-98, pp. 2421-2424, Greece, 1998.

8. H. Choi and W. J. Williams, "Improved time-frequency representation of multicomponent signals using exponential kernels," IEEE Trans. on Acoust., Speech, and Signal Processing, Vol. 37, No. 6, pp. 862-871, June 1989.

9. D. L. Jones and R. G. Baraniuk, "An adaptive optimalkernel time-frequency representation," IEEE Trans. Signal Processing, Vol. 43, No. 10, pp. 2361-2371, Oct. 1995.

10. R. N. Czerwinski and D. L. Jones, "Adaptive conekernel time-frequency analysis," IEEE Trans. Signal Processing, Vol. 43, No. 7, pp. 1715-1719, July 1995.

11. Shie Qian and Dapang Chen, Joint Time-Frequency Analysis Methods and Applications, Prentice-Hall, Upper Saddle River, New Jersey, 1996.

12. P. Daponte and G. Fazio and A Molinaro, "Detection of echoes using time-frequency analysis techniques," IEEE Trans. on Instrumentation and Measurement, Vol. 45, No. 1, Feb. 1996.

13. A. M. Sayeed and D. L. Jones, "Optimal quadratic detection and estimation using generalized joint signal representations," IEEE Trans Signal Processing, Vol. 44, No. 12, Dec. 1996. 


\section{時頻分佈函數於移動式主動感測器 方位估測之應用}

張順雄劉俊成邱志偉

國立台灣海洋大學電機工程學系

\section{摘 要}

由於時頻估測被廣泛應用在雷達、聲納與地震 學等領域, 因此增加時頻估測的精確度一直是科學家 們追求的目標。現行的高解析度時頻估測方式大多是 採用時頻分佈信號。本論文結合多孔徑雷達信號與陣 列信號處理方式, 並利用時頻分佈函數進行主動偵測 器物體的方位估測。由主動偵測器偵測目標物的回應 訊號與分析時間與相位延遲所造成在訊號頻率上的非 䊝態變化, 可以解析出頻率變化的物理特徵值及找出 目標物與參考座標的對應角度與位置, 其可以實際運 用在飛行物與車輛的方位估測。藉由這種方式可以避 免繁雜的多維度傅立葉投射計算、特徵化程序與頻譜 掃描, 並可以有效的減少所需要的動態感測元件。但 是並非所有的時頻分佈函數都適合用於多目標物偵 測, 因爲其會造成高交關項並容易受雜訊影響。因此 本論文提出一種新的時頻分佈函數MACK(Modified Adaptive Cone Kernel) $\circ$ MACK 可以有效的消除交關 項, 且具有良好的時頻分析能力。模擬結果顯示 MACK函數在飛行導航與船隻定位的應用上是相當有 用與可靠的。

關鍵詞：方位估測, 時頻分佈函數, 修正型可適性錐 形核心函數。 